\title{
Typical engineering design of potato micro-sprinkler irrigation in Northern Shanxi
}

\author{
Jiewei $\mathrm{He}^{1,2}$, Zhanqiang Chang ${ }^{1, *}$, Ziyu Wang ${ }^{1,2}$, Jiexun $\mathrm{He}^{3}$, Xue Zhang ${ }^{1,2}$, Xueqi Zhu ${ }^{1,2}$, \\ and Wantian $\mathrm{Zhu}^{1,2}$ \\ ${ }^{1}$ College of Resources, Environment and Tourism, Capital Normal University, Beijing 100101, China \\ ${ }^{2}$ Beijing Laboratory of Water Resources Security, Beijing 100101, China \\ ${ }^{3}$ College of Forestry, Northwest Agriculture and Forestry University,Shaanxi 712100, China
}

\begin{abstract}
The Loess Plateau in the northern part of Shanxi Province has uneven rainfall and large evaporation, so droughts often occur. The drought has restricted the development of the local planting industry and the economy. Micro sprinkler irrigation has the advantages of strong adaptability, saving water, saving labor and land, increasing production, and preventing salinization, which is very suitable for this area.

This micro-sprinkler irrigation design is carried out in typical plots, based on potato plant characteristics, rainfall data over the years, combined with corresponding specifications and actual conditions. This article uses a refraction micro-sprinkler with a spray diameter of $2.4 \mathrm{~m}$. In the water transmission and distribution network, underground pipelines share 1,860 $\mathrm{m}$ of main pipes and sub-main pipes; surface pipelines share $1,200 \mathrm{~m}$ of branch pipes and $90,000 \mathrm{~m}$ of capillary pipes. The design meets the verification indicators of all irrigation groups, conforms to local actual conditions.
\end{abstract}

\section{Introduction}

With the progress of science and technology and the development of economy, water resources have become more and more important, and the concept of water saving has gradually integrated into our life. China is in short supply of water resources, with $2,300 \mathrm{~m}^{3}$ per capita, accounting for only about a quarter of the world. The distribution of water resources is uneven in time and space, and there is a big difference in annual and inter-annual precipitation. Dry and water shortage is the fundamental reason that restricts agricultural development in most areas of China[1].

\section{Overview of the research area}

This design takes the loess plateau in the north of Shanxi as an example, mainly pumping groundwater through the existing mechanical wells, and the cash crop is potato. According to the water source conditions and combined with the actual topographic conditions, the

\footnotetext{
*Corresponding author: changkk1l@tom.com
} 
design is carried out according to $400 \mathrm{~m} \times 450 \mathrm{~m}$. Each well controls a plot as a micro-sprinkler irrigation system.

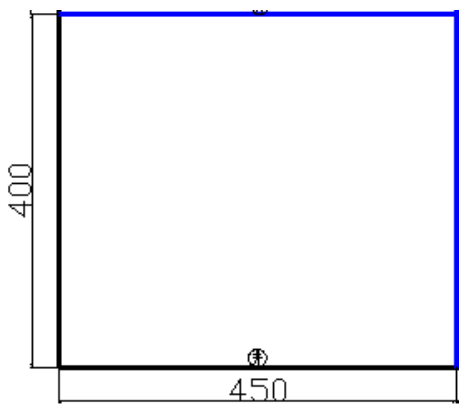

Fig. 1. Research area diagram.

The research area is a continental monsoon climate. According to the data of the weather station, the average annual precipitation was $364.7 \mathrm{~mm}$ (29-year series from 1972 to 2001), and the distribution of water was uneven. The minimum annual rainfall was $244.0 \mathrm{~mm}$ (1972), and the maximum annual rainfall was $564.9 \mathrm{~mm}$ (1973).77\% of annual precipitation is concentrated in June to September.The annual average evaporation is 2028.8mm,groundwater supply mainly comes from meteoric precipitation, surface runoff infiltration to recharge. Single well flow in the project area is $70 \mathrm{~m}^{3} / \mathrm{d}$.

\section{Water balance calculation}

\subsection{Annual precipitation calculation at design frequency}

- $\quad$ Mean annual precipitation

The average annual rainfall of this area was determined by equipluve method. According to GB/T50485-2009 Technical Specifications for Micro irrigation Engineering, the engineering design guarantee rate of the micro-irrigation system is $85 \%$.

According to the Hydrology Calculation Manual of Shanxi Province, its rainfall varies between $350-400 \mathrm{~mm}$. After calculation and investigation, it is determined that the average annual precipitation in the project area is $\mathrm{P}=364.7 \mathrm{~mm}$.

- Coefficient of variation of annual precipitation $C_{V}$

As the annual precipitation variation coefficient $C_{V}$ value has a small regional variation, according to the design requirements of the long series $\left(\mathrm{C}_{V}\right.$ contour map of precipitation in Shanxi Province during 1956-2008), the CV value at the center of the project area is 0.23 .

- $\quad$ Annual precipitation calculation at design frequency

Assume that $\mathrm{P}=85 \%$ design frequency, The center of the research area $\mathrm{Cv}_{\mathrm{V}}=0.23, \mathrm{Cs}=2 \mathrm{Cv}$, can by Pearson typeIIIcurve mode ratio coefficient $\mathrm{Kp}$ value table find out $\mathrm{K} 85 \%=0.538$. Annual precipitation at a design frequency of $85 \%$ in the project area is calculated by the following formula: $\mathrm{P} 85 \%=\mathrm{K} 85 \% \times \mathrm{P}=0.538 \times 364.7=196.2(\mathrm{~mm})$

\subsection{Inflow calculation}

The main water source of research area is groundwater. According to the Report on Detailed Investigation of Groundwater Resources in Shanxi Province and the groundwater exploitation module, the annual amount of exploitable water resources is $268,000 \mathrm{~m}^{3}$. 


\subsection{Water requirement calculation}

This design demand the agricultural irrigation water use:

According to the relevant test data of the Provincial Institute of Water Science and Technology, the water requirement of potatoes is $300-500 \mathrm{~m} 3 / \mathrm{mu}$, combined with the comprehensive analysis of the survey results in project area, set to $350 \mathrm{~m} 3 / \mathrm{mu}$, equivalent to $524.7 \mathrm{~mm}[2]$.

Multiply the monthly distribution ratio of annual precipitation with frequency $\mathrm{P}=85 \%$ in the research area by $364.7 \mathrm{~mm}$ to obtain a monthly distribution table of annual precipitation with design frequency $\mathrm{P}=85 \%$. As shown in Table 2 .

Table 1. Monthly distribution table of annual precipitation when design frequency $\mathrm{P}=85 \%$ in the project area. unit: $\mathrm{mm}$

\begin{tabular}{|c|c|c|c|c|c|c|c|c|c|c|c|c|c|}
\hline Month & Jan & Feb & Mar & Apr & May & Jun & Jul & Aug & Sept & Oct & Nov & Dec & Sum \\
\hline $\begin{array}{c}\text { distribution } \\
\text { ratio }\end{array}$ & 0 & 0.2 & 2.3 & 4.9 & 5.7 & 18.3 & 17.8 & 33.1 & 14.2 & 1.2 & 2.3 & 0.0 & 100.0 \\
\hline $\begin{array}{c}\text { precipitatio } \\
\mathrm{n}\end{array}$ & 0 & 0.4 & 4.5 & 9.6 & 11.2 & 35.9 & 34.9 & 64.9 & 27.9 & 2.4 & 4.5 & 0.0 & 196.2 \\
\hline
\end{tabular}

Effective utilization coefficients $\alpha$ :

Time precipitation $<50 \mathrm{~mm}, \alpha=1.0 ; 50 \mathrm{~mm}<$ Time precipitation $<150 \mathrm{~mm}, \alpha=0.80-0.75$.

The whole growth period of potato was from April to September, and the rainfall in August was $>50 \mathrm{~mm}, \alpha=0.8$; In the remaining months of the growth period, the number of monthly rainfall $<50 \mathrm{~mm}, \alpha=1.0$. The utilization coefficient of irrigation water was 0.85 .

Table 2. Results of irrigation quota calculation.

\begin{tabular}{|c|c|c|c|c|c|c|c|}
\hline $\begin{array}{c}\text { Growing } \\
\text { period }\end{array}$ & $\begin{array}{c}\text { Frequency } \\
(\%)\end{array}$ & $\begin{array}{c}\text { Total } \\
\text { rainfall } \\
(\mathrm{mm})\end{array}$ & $\begin{array}{c}\text { Effective } \\
\text { precipitation } \\
(\mathrm{mm})\end{array}$ & $\begin{array}{c}\text { Water } \\
\text { requirement } \\
(\mathrm{mm})\end{array}$ & $\begin{array}{c}\text { Scale } \\
\text { irrigation } \\
(\mathrm{mm})\end{array}$ & $\begin{array}{c}\text { Utilization } \\
\text { coefficient }\end{array}$ & $\begin{array}{c}\text { Irrigation } \\
\text { water } \\
(\mathrm{Mm} 3)\end{array}$ \\
\hline $\begin{array}{c}4-9 \\
\text { month }\end{array}$ & 23.56 & 196.2 & 171.4 & 524.7 & 353.3 & 0.85 & 26.176 \\
\hline
\end{tabular}

\subsection{Water resource balance calculation}

According to the calculation of water demand, the annual water demand is $261,776 \mathrm{~m}^{3}$ when $\mathrm{P}=85 \%$. The actual annual available water resource is $268,000 \mathrm{~m}^{3}$, so the water inflow exceeds water demand ( $85 \%$ guarantee rate), can meet the water requirements.

\section{Typical engineering design}

\subsection{Determination of parameters of micro-sprinkler irrigation system}

- Irrigation design guarantee rate

According to natural and economic conditions, the irrigation design guarantee rate is determined to be $85 \%$.

- Utilization coefficient of irrigation water - $\eta$ 
The utilization coefficient of irrigation water under micro-sprinkler irrigation was $\geq 0.85$ (GB/T50485-2009 Technical Specification for Micro-irrigation Engineering), set to 0.85.

- Design soil moisture ratio - $\rho$

According to the data, the value range of vegetables is $70-100 \%$, set to $70 \%$.

- Design the water consumption intensity of crops - Ia

Potato is a vegetable and food crop. Looking up the table, The designed water consumption intensity of $5 \sim 8 \mathrm{~mm} / \mathrm{d}$, set to $5 \mathrm{~mm} / \mathrm{d}$.

- Design the depth of wetting layer $-Z$

According to the requirements of the specification and the actual situation, the depth of the wetting layer is planned to be $0.8 \mathrm{~m}$ in this design.

- $\quad$ Field water capacity and upper and lower limits of water content

Soil field water holding rate $24 \%$.

The upper limit is farmland holding $90 \%, \theta \max =24 \% \times 90 \%=21.6 \%$;

The lower limit is farmland holding $65 \%, \theta \mathrm{min}=24 \% \times 65 \%=15.6 \%$.

- Working hours on design day of micro-sprinkler irrigation system

According to the specification, generally should not be greater than $22 \mathrm{~h}$, select $22 \mathrm{~h}$.

- Deviation of irrigation plot flow

Deviation of irrigation plot flow qv $=20 \%$.

\subsection{Formulation of irrigation system}

Select the refractive sprinkler, the working pressure was $150 \mathrm{kPa}$, the flow rate was $40 \mathrm{~L} / \mathrm{h}$, the spraying diameter was $2.4 \mathrm{~m}$, the micro sprinkler head spacing was $2 \mathrm{~m}$, adopt single nozzle arrangement, and the effective wetting area was $15 \mathrm{~m}^{2}$. The spacing of plants and rows was $0.3 \mathrm{~m} \times 0.7 \mathrm{~m}$.

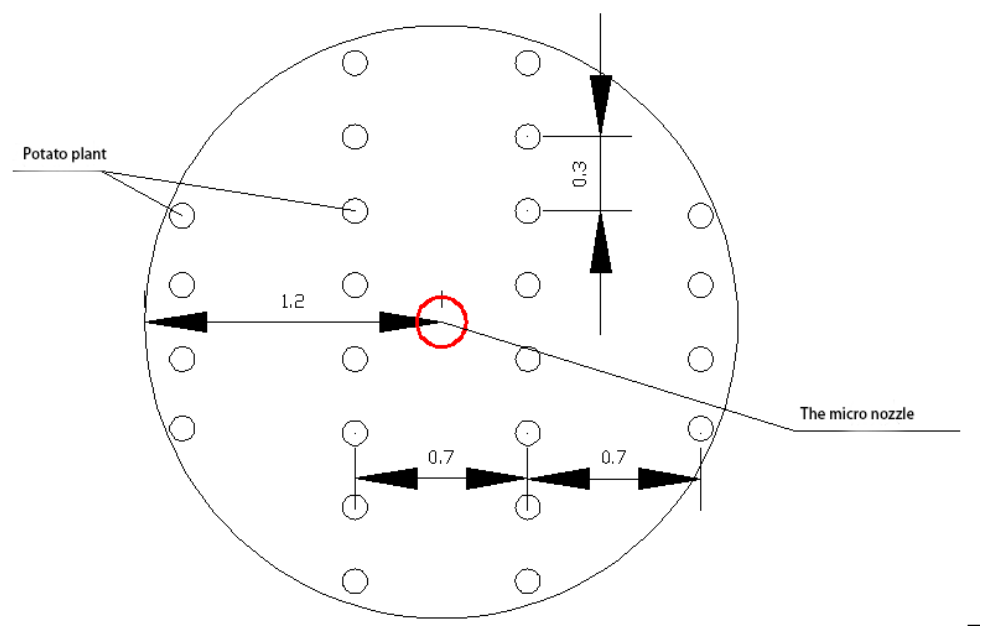

Fig. 2. Schematic diagram of single micro sprinkler covering.

\subsubsection{Maximum net irrigation quota}

$$
\begin{gathered}
\rho_{\omega}=\frac{\mathrm{NpSeW}}{\mathrm{SpS}} \times 100 \%=80 \% \\
\mathrm{~m}_{\max }=1000 \gamma \mathrm{Z} \rho_{\omega}\left(\theta_{\max }-\theta_{\min }\right)=48.05 \mathrm{~mm}
\end{gathered}
$$


where $\rho_{\omega}$ is wetting ratio, $\mathrm{m}_{\max }$ is maximum net irrigation quota. Among them $\mathrm{Np}$ is number of micro-sprinklers per crop; $\mathrm{W}$ is wetting band width; Se is micro nozzle spacing. $\mathrm{Sp}, \mathrm{SR}$ are row spacing and column spacing of the plant; $\gamma$ is soil bulk density, set to 1.43 .

\subsubsection{Formulation of irrigation system}

$$
\begin{aligned}
& \mathrm{T}=\frac{\mathrm{m}_{\max }}{\mathrm{Ia}} \approx 9 \mathrm{~d} \\
& \mathrm{~m}_{\text {gro }}=\frac{\mathrm{T} \times \mathrm{Ia}}{\eta}=52.94 \\
& \mathrm{t}=\frac{\mathrm{m}_{\mathrm{gro}} \mathrm{SeSl}}{\eta \mathrm{q}}=6.2 \mathrm{~h}
\end{aligned}
$$

where $\mathrm{T}$ is irrigation cycle; $\mathrm{m}_{\text {gro }}$ is actual water consumption for irrigation; $\mathrm{t}$ is duration of each irrigation; and $\mathrm{Sl}$ is capillary interval.

\subsubsection{Determine the distribution of branch and capillary head difference}

$$
\begin{gathered}
h_{\text {max }}=\left(1+0.65 \mathrm{q}_{\mathrm{v}}\right)^{1 / \mathrm{x}} h \mathrm{a}=20.16 \mathrm{~m} \\
h_{\min }=\left(1-0.35 \mathrm{q}_{\mathrm{v}}\right)^{1 / \mathrm{x}} \text { ha }=10.58 \mathrm{~m} \\
\Delta \mathrm{Hs}=\mathrm{h}_{\max }-\mathrm{h}_{\min }=7.58 \mathrm{~m}
\end{gathered}
$$

The head loss of the capillary and branch pipes is distributed according to 55:45[3].

$$
\Delta \mathrm{H}_{\text {cap }}=4.169 \mathrm{~m} \quad \Delta \mathrm{H}_{\text {bra }}=3.411 \mathrm{~m}
$$

\subsubsection{Calculate the capillary limit length}

$$
\mathrm{L}_{\mathrm{m}}=\operatorname{INT}\left(\frac{5.446 \Delta \mathrm{H}_{\mathrm{cap}} \mathrm{D}^{4.75}}{\mathrm{KS}_{\mathrm{qa}}{ }^{1.75}}\right)^{0.364} \mathrm{~S}=86 \mathrm{~m}
$$

The limit length of capillary was calculated according to the head distribution, Through calculation the limit length is $86 \mathrm{~m}$, for the convenience of layout, it is set to $75 \mathrm{~m}$.

\subsection{5 working system of micro sprinkler irrigation system}

$$
\mathrm{N}=\frac{\mathrm{CT}}{\mathrm{t}}=31.9
$$

The maximum number of irrigation groups was 31.9 . according to the actual situation, set to 30 .

\subsubsection{Irrigation pipeline arrangement}

According to the length of the capillary and the number of irrigation groups calculated above, the reasonable pipeline layout is determined.as shown in the Fig. 3. 


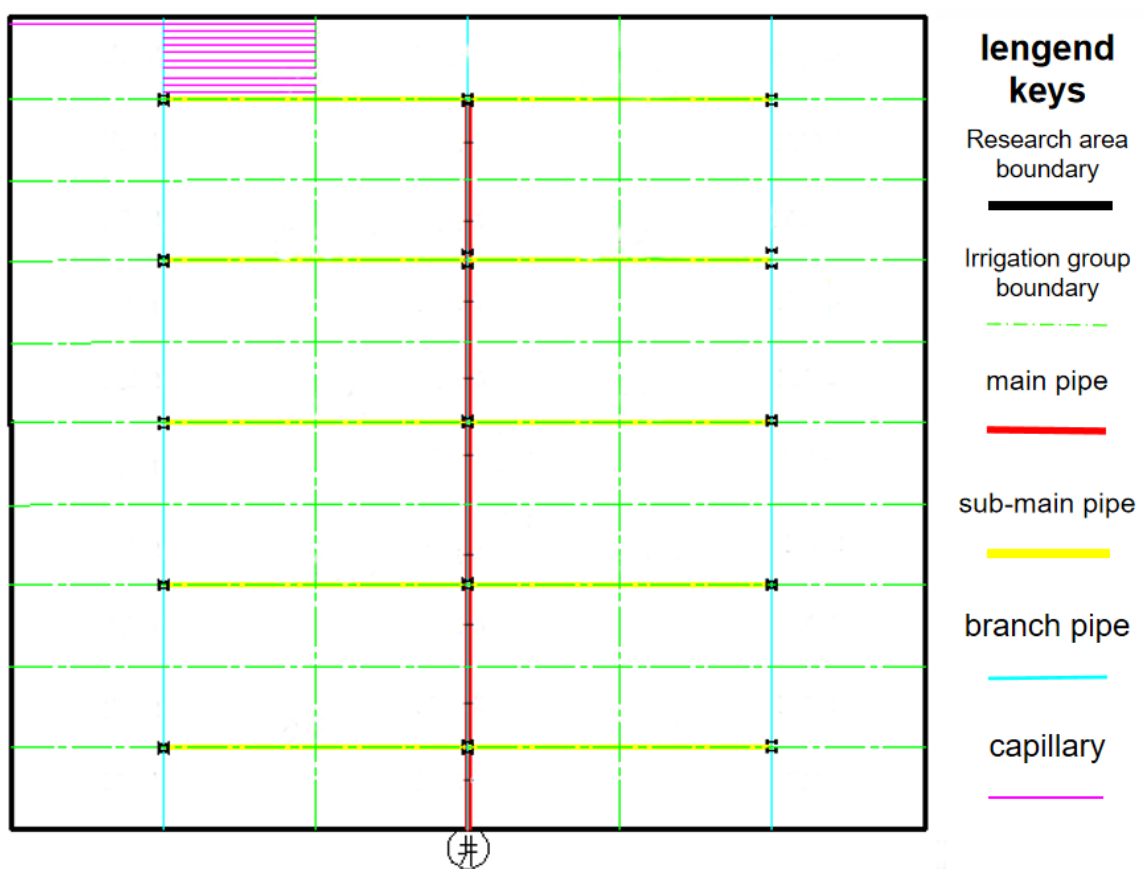

Fig. 3. Pipeline layout of typical plots.

\section{Summary and conclusion}

According to the characteristics of potato plants, rainfall data over the years, combined with corresponding specifications and actual conditions. The calculation of water balance shows that the micro-sprinkler irrigation system can be applied in this area. Then, by controlling the pressure difference between the head and tail of the capillary and calculating the head loss along the way, a reasonable piping arrangement and irrigation system were determined.

The research area covers an area of $400 \times 450 \mathrm{~m}^{2}$. Adopt a refraction nozzle with a spraying diameter of $2.4 \mathrm{~m}$. The design length of a single capillary is $75 \mathrm{~m}$, and one is laid $2 \mathrm{~m}$ apart, a total of $90,000 \mathrm{~m}$. The branch pipe connected to the capillary is $1200 \mathrm{~m}$, and the main and sub-main pipes are $1,860 \mathrm{~m}$.

It is of great significance to develop the most suitable water-saving irrigation technology in accordance with local conditions. Areas with similar climatic conditions can refer to the detailed steps in this article for design.

\section{References}

1. Wenjing $\mathrm{Xu}$. Research on development trend of water-saving irrigation in China [J]. Chinese Agricultural Science Bulletin, 2016, 32 (11):184-187.

2. Huang Fei. High yield cultivation techniques of sprinkler irrigation potato $[\mathrm{J}]$. Modern Agriculture, 2015 (2):46-47.

3. Kouman S. Koumanov. Schwankl. Spatial and temporal distribution of root water uptake of an almond tree under micro sprinkler irrigation [J].Irrig Sci (2006)24:267-278. 